www.volsu.ru

DOI: https://doi.org/10.15688/jvolsu11.2018.1.3

UDC 577, 57.032, 57.087.3

LBC 28.03, 28c, 28.071

\title{
THE NON-INVASIVE SYSTEM TO CONTROL MORPHOGENESIS OF PLANARIA AS AN ALTERNATIVE APPROACH TO BIOASSESSMENT
}

\author{
Ulyana M. Vorobyeva \\ Pushchino State Institute of Natural Sciences, Pushchino, Russian Federation \\ Kirill N. Novikov \\ Lomonosov Moscow State University, Moscow, Russian Federation \\ Olga V. Burlakova \\ Lomonosov Moscow State University, Moscow, Russian Federation \\ Viktor I. Emelyanenko \\ Pushchino State Institute of Natural Sciences, Pushchino, Russian Federation \\ Kharlampiy P. Tiras \\ Pushchino State Institute of Natural Sciences, Pushchino, Russian Federation
}

Abstract. The published study tests our own chemical luminescence Planaria accompanying regeneration processes in combination with methods of in vivo fixation of their structure using non-invasive computer morphometry. As a result, we propose a new system of online remote control of morphogenesis in Planaria regeneration. This system is promising for primary screening of drugs - proliferation regulators.

Key words: biomonitoring, biotesting, molecular toxicology, regeneration, Girardia tigrina.

УДК $577,57.032,57.087 .3$

ББК $28.03,28 \mathrm{c}, 28.071$

СИСТЕМА НЕИНВАЗИВНОГО КОНТРОЛЯ МОРФОГЕНЕЗА ПЛАНАРИЙ КАК АЛЬТЕРНАТИВНЫЙ ПОДХОД К БИОТЕСТИРОВАНИЮ ${ }^{1}$

Ульяна Максимовна Воробьева

Пущинский государственный естественно-научный институт, г. Пущино, Российская Федерация

\section{Кирилл Николаевич Новиков}

Московский государственный университет им. М.В. Ломоносова, г. Москва, Российская Федерация

Ольга Владимировна Бурлакова

Московский государственный университет им. М.В. Ломоносова, г. Москва, Российская Федерация

Виктор Иванович Емельяненко

Пущинский государственный естественно-научный институт, г. Пущино, Российская Федерация

\section{Харлампий Пантелеевич Тирас}

Пущинский государственный естественно-научный институт, г. Пущино, Российская Федерация 
Аннотация. В публикуемом исследовании была протестирована собственная хемилюминесценция планарий, сопровождающая процессы регенерации, в комплексе с методиками прижизненной фиксации их структуры с помощью неинвазивной компьютерной морфометрии. По итогу была предложена новая система online дистанционного контроля морфогенеза при регенерации планарий. Данная система представляется перспективной для первичного скрининга лекарственных препаратов - регуляторов пролиферации.

Ключевые слова: биомониторинг, биотестирование, молекулярная токсикология, regeneration, Girardia tigrina.

Регенерация пресноводных плоских червей - планарий - давно используется как тестсистема для альтернативного биотестирования лекарственных препаратов - регуляторов клеточной пролиферации [2]. Она основывалась на неинвазивной регистрации регенерации методом прижизненной компьютерной морфометрии (ПКМ) [2; 3]. В настоящей работе эта тест-система дополнена регистрацией собственной сверхслабой фотонной эмиссии (ССФЭ).

Собственная хемилюминесценция или ССФЭ сопровождает различные функциональные процессы в живых системах. Ранее был описан феномен ССФЭ при регенерации планарий [4].

Целью данной работы была апробация новой тест-системы, сочетающей регистрацию ССФЭ и ПКМ на одной и той же группе регенерирующих планарий.

\section{Материалы и методы}

Работа проведена на бесполой лабораторной расе планарий Girardia tigrina, которых содержали в комнатных условиях при температуре $20-210^{\circ} \mathrm{C}$. Животных кормили еженедельно личинками двукрылых, а перед экспериментами планарии голодали в течение недели.

Регистрацию ССФЭ проводили с помощью люминометра Биотокс-7а. Прибор оснащен фотоумножителем 9750QB/1 (9750QB/1, EMI Electronics LTD, Middlesex, UK) с областью спектральной чувствительности 380-710 нм, с максимумом в сине-зеленой области, 420-500 нм. Измерения проводили при температуре $21,0 \pm 0,2{ }^{\circ} \mathrm{C}$, в режиме счета фотонов с интервалом записи данных 1 с. Дальнейший анализ результатов проводили по ранее описанному методу [4].

Группу из 30 планарий сразу после декапитации помещали во флакон для сцинцил- ляционного счета в 10 мл водного раствора люцигенина $\left(10^{-9} \mathrm{M}\right)$ и начинали регистрацию ССФЭ.

В специальных экспериментах регистрацию ССФЭ у планарий в контрольной и экспериментальной группе проводили параллельно на двух люминометрах Биотокс-7а.

Также на двух люминометрах сравнивали ССФЭ при одно- и многократной перерезке планарий.

Регенерацию регистрировали методом прижизненной компьютерной морфометрии (ПКМ). Метод базируется на регистрации фотоконтраста между старыми (пигментированными) и новыми (непокрытыми пигментом) частями тела регенерирующих планарий. Для получения изображений планарий применяли бинокулярный компьютерный микроскоп Stemi 2000C, оборудованный видеокамерой AxioCam MRc (Zeiss). Регенерацию вызывали ампутацией головной части тела планарии и регистрировали через 72 и 120 часов после перерезки.

Оцифрованные изображения регенерирующих планарий обрабатывали в программе Plana 5.0, которая позволяет анализировать электронные изображения планарий и определить площади проекции тела регенеранта и бластемы. В качестве критерия регенерации использовали отношение площади бластемы к общей площади планарии на определенный день регенерации [3].

Митотический индекс в ходе регенерации определяли путем подсчета митотических фигур в суспензии клеток планарий [5]. Подсчитывали число метафаз на 1000 клеток (митотический индекс) в течение 24 часов после перерезки на фоне действия колхицина. Для визуализации митотических фигур использовали краситель Hoehst 33342. Метафазы регистрировали с помощью флюоресцентного микроскопа AxioVert 200M (Zeiss). 
Статистический анализ результатов определения митотического индекса проводили по критерию Манна-Уитни для малых групп. Результаты анализа изображений методом ПКМ проводили с помощью пакета программ SygmaPlot 9.0 [1].

Определяли величину средней (М), ошибку средней (m), вычисляли доверительный интервал для уровня значимости 0,95 . Сравнение средних величин проводили с помощью Т-критерия Стьюдента [2].

\section{Результаты и их обсуждение}

Работу проводили на одной и той же группе планарий. Были последовательно исследованы два явления, которые сопровождают процессы регенерации: собственная хемилюминесценция (ССФЭ) и морфогенез в течение 120 часов после декапитации.

После операции декапитации контрольную и экспериментальную группы помещали в люминометр на 24 часа. Всплеск ССФЭ наблюдали сразу после перерезки в ходе регенерации, затем в течение примерно 2-4 часов ССФЭ релаксировала до уровня излучения интактного животного. Через 10-12 часов после декапитации наблюдали второй всплеск ССФЭ.
Далее регистрировали динамику роста бластемы у экспериментальной и контрольной групп через 72 и 120 часов после декапитации методом ПКМ. Метод базируется на регистрации фотоконтраста между пигментированными и непокрытыми пигментом частями тела регенерирующего животного [3].

Для апробации системы было изучено действие биологически активного пептида CLV3 в концентрации $10^{-9} \mathrm{M}$ - стимулятора роста растений, выделенного из корней резуховидки Таля Arabidopsis thaliana. Исследование ССФЭ проводили параллельно на двух группах (экспериментальной и контрольной) из 30 декапитированных животных на двух люминометрах Биотокс-7а. Результаты представлены на рисунке 1 .

В первые два часа пептид ускорял выход в релаксацию уровня ССФЭ в два раза по сравнению с контролем. Также вдвое был выше уровень ССФЭ на 12-й час после операции под действием пептида. Эффект стимуляции пролиферации был подтвержден методом подсчета митотического индекса (МИ) в суспензии клеток планарий. МИ под действием пептида $\left(10^{-9} \mathrm{M}\right)$ вырос на 17 \% по сравнению с контролем.

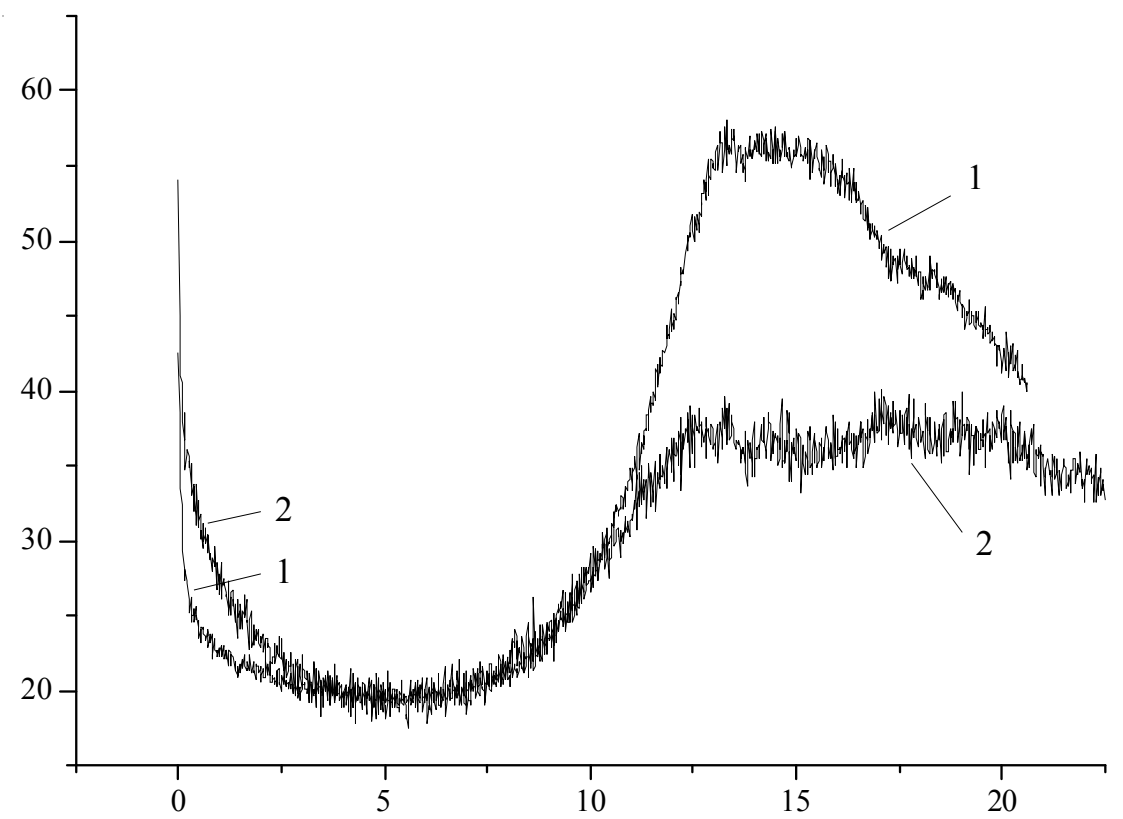

Рис. 1. Действие пептида CLV3 на ССФЭ планарий G. tigrina в первые сутки после декапитации.

По оси абсцисс - время регенерации в часах. По оси ординат - интенсивность сверхслабой фотонной эмиссии (ССФЭ) в фотонах в сек. 1 - динамика ССФЭ в ходе регенерации головного конца тела планарий под действием пептида CLV3 $\left(10^{-9} \mathrm{M}\right) .2$ - динамика ССФЭ в ходе регенерации головного конца тела планарий в контроле. 
Далее эффект стимуляции регенерации пептидом CLV3 был зарегистрирован на 72 и 120 час после перерезки в пяти сериях экспериментов методом ПКМ (табл.).

В первые 24 часа после перерезки в теле планарий регистрировали 1-2 пика пролиферации стволовых клеток - необластов [6]. Мы предположили, что всплеск ССФЭ на 10-12 час регенерации связан с пиком пролиферации необластов в ходе морфогенеза.

Для подтверждения этой связи были проведены дополнительные эксперименты. Были проведены эксперименты по многократной перерезке планарий для увеличения числа раневых поверхностей, поскольку количество делящихся клеток прямо зависит от их числа.

Сравнивали величину фотонной эмиссии у планарий после одно- и троекратной перерезки, при которых формируется 2 и 6 регенерационных бластем. В результате было зарегистрировано удвоение уровня ССФЭ на 13-15 час после перерезки при многократной перерезке. Тем самым, была показана прямая корреляция пика ССФЭ с числом раневых поверхностей, что прямо связано с числом пролиферирующих необластов.

Об этом же свидетельствовали эксперименты по прямому измерению митотического индекса (МИ), под действием пептида CLV3 в первые 24 часа после декапитации. При этом также рост МИ в среднем на $17 \%$ выше по сравнению с контролем.

Таким образом, была протестирована новая система последовательного дистанционного контроля процесса морфогенеза при регенерации планарий. Данная система представляется перспективной для первичного скрининга лекарственных препаратов - регуляторов пролиферации.

\section{ПРИМЕЧАНИЕ}

${ }^{1}$ Исследование выполнено при финансовой поддержке РФФИ в рамках научного проекта № 1529-01135 офи_м, а также в рамках Проекта Госзадания Минобранауки № 6.12959.2018/12.1.

\section{СПИСОК ЛИТЕРАТУРЫ}

1. Влияние слабого магнитного поля на скорость регенерации планарий Dugesia tigrina / Х. П.Тирас [и др.] // Биофизика. - 1996. - Т. 41, № 4. - C. 826-831.

2. Новиков, Д. А., Статистические методы в медико-биологическом эксперименте (типовые случаи) / Д. А. Новиков, В. В. Новочадов. - Волгоград : Изд-во ВолГМУ, 2005. - 84 с.

3. Собственная хемилюминесценция необластов планарии в процессе регенерации / Х. П. Тирас [и др.] // Биофизика. - 2015. - Т. 60, № 5. - C. 975-980.

4. Тирас, Х. П. Тест-система для доклинического исследования медицинской и экологической безопасности на основе регенерации планарий / Х. П. Тирас, К. Б. Асланиди // Труды Тульского государстевнного университета. - Тула : Изд-во ТулГУ, 2013. - С. 63.

5. Тирас, Х. П. Регламентация условий культивирования планарий и параметров морфометрического эксперимента / Х. П. Тирас, К. Б. Асланиди // Современные проблемы науки и образования. 2016. - № 6 .

\section{Действие пептида CLV3 на регенерацию планарий}

\begin{tabular}{|c|c|c|c|c|c|}
\hline \multirow{2}{*}{$\begin{array}{c}\text { Серия } \\
\text { опытов } \\
\end{array}$} & \multirow{2}{*}{$\begin{array}{c}\text { Критерий } \\
\text { регенерации }\end{array}$} & \multicolumn{2}{|c|}{3 день регенерации } & \multicolumn{2}{|c|}{5 день регенерации } \\
\hline & & Опыт & Контроль & Опыт & Контроль \\
\hline \multirow[t]{2}{*}{1} & $\mathrm{M} \pm \mathrm{m}$ & $0,025 \pm 0,006$ & $0,018 \pm 0,003$ & $0,049 \pm 0,01$ & $0,041 \pm 0,007$ \\
\hline & $\mathrm{T}$ & 3,851 & & 2,504 & \\
\hline \multirow[t]{2}{*}{2} & $\mathrm{M} \pm \mathrm{m}$ & $0,029 \pm 0,005$ & $0,027 \pm 0,004$ & $0,044 \pm 0,007$ & $0,042 \pm 0,006$ \\
\hline & $\mathrm{T}$ & 1,251 & & 1,186 & \\
\hline \multirow[t]{2}{*}{3} & $\mathrm{M} \pm \mathrm{m}$ & $0,022 \pm 0,003$ & $0,016 \pm 0,002$ & $0,041 \pm 0,005$ & $0,032 \pm 0,004$ \\
\hline & $\mathrm{T}$ & 7,158 & & 6,904 & \\
\hline \multirow[t]{2}{*}{4} & $\mathrm{M} \pm \mathrm{m}$ & 0,001 & & 0,001 & \\
\hline & $\mathrm{T}$ & $0,018 \pm 0,003$ & $0,016 \pm 0,002$ & $0,039 \pm 0,007$ & $0,031 \pm 0,007$ \\
\hline \multirow[t]{2}{*}{5} & $\mathrm{M} \pm \mathrm{m}$ & 2,102 & & 3,303 & \\
\hline & $\mathrm{T}$ & $0,025 \pm 0,009$ & $0,029 \pm 0,006$ & $0,044 \pm 0,01$ & $0,040 \pm 0,007$ \\
\hline
\end{tabular}


6. Wenemoser D., Planarian regeneration involves distinct stem cell responses to wounds and tissue absence / D. Wenemoser, P. W. Reddien // Developmental biology. - 2010. - Vol. 344, № 2. P. 979-991.

\section{REFERENCES}

1. Tiras Kh.P., Skrebnitskaya L.K., Ilyasova E.N., Klimov A.A., Lednev V.V. Vliyanie slabogo magnitnogo polya na skorost regeneratsii planariy Dugesia tigrina [The Influence of Weak Magnetic Fields on the Regeneration of Planaria Dugesia tigrina]. Biophysics, 1996, vol. 41, no. 4, pp. 826-831.

2. Novikov D.A., Novochadov V.V. Statisticheskie metody $v$ mediko-biologicheskom eksperimente (tipovye sluchai) [Statistical Methods in Medical-Biological Experiments (Typical Cases)]. Volgograg, Izd-vo VolgGMU, 2005. 84 p.

3. Tiras K.P., Gudkov S.V., Emelyanenko V.I., Aslanidi K.B. Sobstvennaya khemilyuminestsentsiya neoblastov planarii v protsesse regeneratsii [Autochemiluminescence of Planarian Neoblasts During Regeneration]. Biophysics, 2015, vol. 60, no. 5, pp. 975-980.

4. Tiras K.P., Aslanidi K.B. Test-sistema dlya doklinicheskogo issledovaniya meditsinskoy i ekologicheskoy bezopasnosti na osnove regeneratsii planariy [Test System for Preclinical Study of Medical and Environmental Safety Based on Planaria Regeneration]. Trudy Tulskogo gos. unta, 2013, p. 63.

5. Tiras Kh.P., Aslanidi K.B. Reglamentatsiya usloviy kultivirovaniya planariy i parametrov morfometricheskogo eksperimenta [Regulatogy Conditions for Cultivation of Planaria and Morphometric Parameters of the Experiment]. Sovremennye problemy nauki i obrazovaniya, 2016, no. 6.

6. Wenemoser D., Reddien P.W. Planarian regeneration involves distinct stem cell responses to wounds and tissue absence. Developmental biology, 2010, vol. 344, no. 2, pp. 979-991.

\section{Information about the Authors}

Ulyana M. Vorobyeva, Master, Laboratory of Functional Bio-morphology, Pushchino State Institute of Natural Sciences, Russian Academy of Sciences, Institutskaya St., 3, 142290 Pushchino, Russian Federation,Tiras1950@yandex.ru.

Kirill N. Novikov, Doctor of Sciences (Biology), Leading Researcher, Laboratory of Physicsand-Chemistry of Biological Membranes, Lomonosov Moscow State University, Leninskie gory St., 1, 119991 Moscow, Russian Federation, kirniknov@yandex.ru.

Olga V. Burlakova, Candidate of Sciences (Biology), Leading Researcher, Department of Embryology, Lomonosov Moscow State University, Leninskie gory St., 1, 119991 Moscow, Russian Federation, kirniknov@yandex.ru.

Viktor I. Emelyanenko, Candidate of Sciences (Physics and Mathematics), Senior Researcher, Laboratory of Isotopic Research, Institute of Theoretical and Experimental Biophysics, Russian Academy of Sciences, Institutskaya St., 3, 142290 Pushchino, Russian Federation, emelyane@rambler.ru.

Kharlampiy P. Tiras, Candidate of Sciences (Biology), Head of the Laboratory of Functional Biomorphology, Pushchino State Institute of Natural Sciences, Russian Academy of Sciences, Institutskaya St., 3, 142290 Pushchino, Russian Federation, Tiras1950@yandex.ru.

\section{Информация об авторах}

Ульяна Максимовна Воробьева, магистр лаборатории функциональной биоморфологии, Пущинский государственный естественно-научный институт, Институт теоретической и экспериментальной биофизики РАН, ул. Институтская, 3, 142290 г. Пущино, Московская область, Российская Федерация, Tiras1950@yandex.ru.

Кирилл Николаевич Новиков, доктор биологических наук, ведущий научный сотрудник лаборатории физико-химии биологических мембран, биологический факультет, Московский государственный университет им. М.В. Ломоносова, Ленинские горы, 1, 119991 г. Москва, Российская Федерация, kirniknov@yandex.ru. 


\section{БИОЛОГИЯ И БИОТЕХНОЛОГИЯ}

Ольга Владимировна Бурлакова, кандидат биологических наук, ведущий научный сотрудник кафедры эмбриологии, биологический факультет, Московский государственный университет им. М.В. Ломоносова, Ленинские горы, 1, 119991 г. Москва, Российская Федерация, kirniknov@yandex.ru.

Виктор Иванович Емельяненко, кандидат физико-математических наук, старший научный сотрудник лаборатории изотопных исследований, Институт теоретической и экспериментальной биофизики РАН, ул. Институтская, 3, 142290 г. Пущино, Московская область, Российская Федерация, emelyane@rambler.ru.

Харлампий Пантелеевич Тирас, кандидат биологических наук, заведующий лабораторией функциональной биоморфологии, Пущинский государственный естественно-научный институт, Институт теоретической и экспериментальной биофизики РАН, ул. Институтская, 3, 142290 г. Пущино Московской области Российская Федерация, Tiras1950@yandex.ru. 